\title{
RESEARCH GIVES INSIGHT INTO DENTISTS' ATTITUDE TO MARKETING
}

A recent study into the attitudes and actions of dentists in regard to marketing their practices reveals results that support the theory that many dental professionals have neither the knowledge nor the tools to conduct a co-ordinated marketing effort. Although there is a clear desire to improve (more than 89\% of dentists indicated their wish to do so), in the main dentists and managers lack the requisite skills and resources. The study also indicated a failure amongst professionals to adequately monitor the necessary data to understand the success of their marketing efforts in terms of return on investment (ROI).

The need to retain patient numbers as well as attract new patients remains vital to the health of UK dental practices. With the continuing growth in corporate penetration and uncertainty around the new contract, the need for high street practices to take control of their marketing proposition is more important than ever. In addition, the ease of access to digital channels is making communication with patients increasingly complex.

These factors have created a 'perfect storm' which has fuelled the desire of dentists and managers to understand and improve their systems for communication and tracking marketing performance, and recent research conducted by Software of Excellence confirms that $93.6 \%$ of those surveyed want to acquire new patients and $89.4 \%$ want to
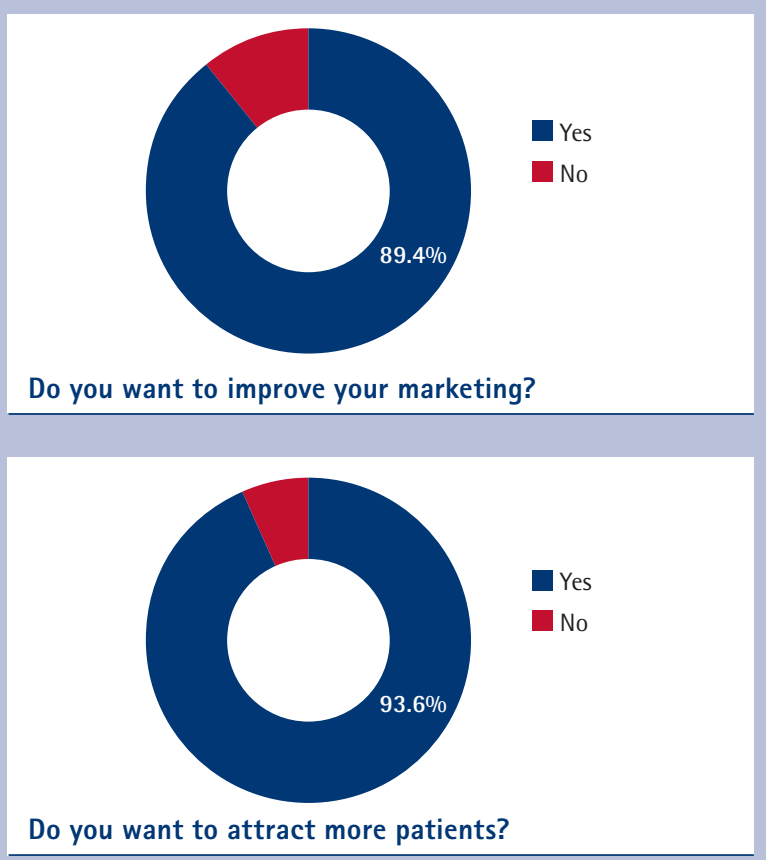

improve their marketing.

However, figures from the same survey have discovered a disconnect between the wish to attract more patients and market services more effectively on the one hand, and the knowledge and resources to do so on the other. In fact statistics show that $77 \%$ of those questioned have no plan of how they will achieve either goal. With a third of UK practices spending less than $£ 1,000$ per annum on marketing and almost half not knowing what their marketing spend is, there is a clear shortfall between the desire to improve marketing and the practical application of effective tools.

In terms of attracting new patients it is unsurprising that patient recommendation remains the most popular method of gaining new patients for $75 \%$ of dentists. But the research data shows that although dentists understand the value of patient recommendation, less than a third routinely ask for specific reviews and only 20\% regularly ask for general feedback about their practice.

There has always been an appreciation of the impact and value of patient testimonials but access to digital communication channels is changing the way in which this feedback is being collected and distributed. There is a growing understanding of the value of using patient testimonials on websites and through social media channels, but the research shows that uptake of these opportunities is relatively slow and almost half of respondents admitted to not using patient testimonials to promote their practice. This means that although dentists may be asking for and collecting patient recommendations, they are missing out on the
SOFTWARE OF EXCELLENCE AשHENRY SCHEIN ${ }^{\circledR}$ Company full potential of using this resource to best effect.

Those who undertake marketing activity, often face challenges in terms of coordinating, executing and monitoring campaigns. Fewer than $40 \%$ undertake any kind of data segmentation before launching a campaign, less than a quarter set any targets by which to measure success and less than half track the results, with many admitting to relying on 'gut feeling' to assess whether a campaign has been successful.

The failure to accurately measure results is put down to a number of barriers such as a lack of knowledge about how to track and monitor. However, many also indicated that such measurement was either too time consuming and complicated or the data to carry out such monitoring was not easily accessible, resulting in an inability to gain any indication of the return on investment from specific campaigns.

Marketing for dental practices is growing in importance as the landscape within which practices operate continues to shift. The need to differentiate and attract patients is more important than ever, but the need to understand how resources are being spent, with defined objectives and easy-to-use methods of monitoring success, are vital if practices are to allocate budgets wisely.

The full results from Software of Excellence's survey will be published in a White Paper this summer. To request a copy of the White Paper or to find out more about new EXACT V12, which addresses some of the marketing challenges faced by practices, email sales@soe.uk.com. 